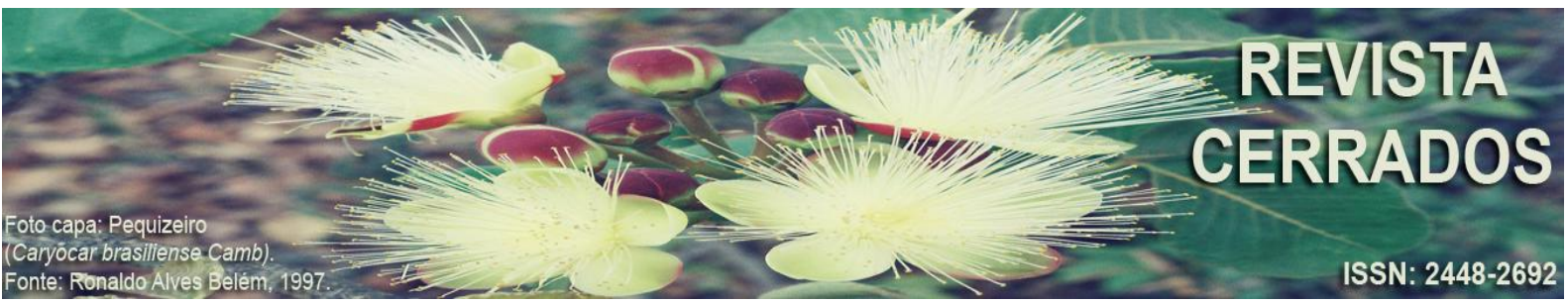

\title{
BRASÍLIA, LUZIÂNIA E AS REPERCUSSÕES TERRITORIAIS DE UMA METROPOLIZAÇÃO (IN)DESEJADA
}

\section{BRASILIA, LUZIANIA AND REPERCUSSIONS OF A TERRITORIAL METROPOLIZATION (UN)DESIRED}

\section{BRASILIA, LUZIANIA Y REPERCUSIONES TERRITORIALES DE UN METROPOLIZACIÓN (NO)DESEADO}

\author{
Bruno Augusto de Souza \\ Universidade Federal de Goiás - UFG \\ E-mail: <b.augustodesouza@gmail.com>. \\ Marcelo de Mello \\ Universidade Estadual de Goiás - UEG \\ E-mail: 〈ueg.marcelo@gmail.com>.
}

\begin{abstract}
Resumo
O processo de transferência da capital federal do Rio de Janeiro para Brasília promoveu um expressivo fluxo migratório no território goiano. Os dados do Instituto Brasileiro de Geografia e Estatística (IBGE) indicam que processos migratórios centrados na capital da república ainda repercutem no crescimento populacional de municípios goianos localizados no entorno do Distrito Federal. Entre os municípios goianos afetados pela construção de Brasília, Luziânia aparece de maneira destacada, pois perdeu parte de seu território para a construção de Brasília e, posteriormente, foi fragmentado para a criação de outros cinco municípios. A proximidade com Brasília fez com que conjuntos habitacionais fossem construídos em Luziânia para arrefecer a pressão por moradia no interior do Distrito Federal. Os Conjuntos Habitacionais, por sua vez, originaram três dos cinco municípios criados por meio do parcelamento do território de Luziânia e são fundamentais para o entendimento de um processo de metropolização centrado em Brasília. Este contexto marcado por fragmentações territoriais e por expressivos movimentos migratórios promoveu a elaboração de um conceito jurídico desenvolvido para possibilitar a gestão de processos de metropolização que envolvem municípios de mais de uma Unidade Federativa. Esta figura jurídica é a Região Integrada de Desenvolvimento.
\end{abstract}

Palavras-chave: Cidade; Fragmentação territorial; Metropolização. 


\begin{abstract}
The process of transferring the federal capital from Rio de Janeiro to Brasilia promoted a significant migratory flow in the territory of Goiás. Data from the Brazilian Institute of Geography and Statistics (IBGE) indicate that migratory processes centered on the capital of the republic still have repercussions on the population growth of municipalities located in the vicinity of the Federal District. Among the municipalities affected by the construction of Brasilia, Luziânia appears prominently, since it lost part of its territory for the construction of Brasília and was later fragmented to create five other municipalities. The proximity to Brasília caused housing projects to be built in Luziânia to cool down the pressure for housing in the interior of the Federal District. The Housing Sets, in turn, originated three of the five municipalities created by means of the subdivision of the territory of Luziânia and are fundamental for the understanding of a process of metropolization centered in Brasília. This context marked by territorial fragmentation and by expressive migratory movements promoted the elaboration of a legal concept developed to enable the management of processes of metropolization that involve municipalities of more than one Federative Unit. This legal figure is the Integrated Development Region.
\end{abstract}

Keywords: City; Territorial fragmentation; Metropolization.

\title{
Resumen
}

El proceso de transferencia de la capital federal de Río de Janeiro a Brasilia promovió un expresivo flujo migratorio en el territorio goiano. Los datos del Instituto Brasileño de Geografía y Estadística (IBGE) indican que procesos migratorios centrados en la capital de la república aún repercuten en el crecimiento poblacional de municipios goianos ubicados en el entorno del Distrito Federal. Entre los municipios goianos afectados por la construcción de Brasilia, Luziânia aparece de manera destacada, pues perdió parte de su territorio para la construcción de Brasilia y posteriormente fue fragmentado para la creación de otros cinco municipios. La proximidad con Brasilia hizo que conjuntos habitacionales fueran construidos en Luziânia para enfriar la presión por vivienda en el interior del Distrito Federal. Los Conjuntos Habitacionales, a su vez, originaron tres de los cinco municipios creados por medio del parcelamiento del territorio de Luziânia y son fundamentales para el entendimiento de un proceso de metropolización centrado en Brasilia. Este contexto marcado por fragmentaciones territoriales y por expresivos movimientos migratorios promovió la elaboración de un concepto jurídico desarrollado para posibilitar la gestión de procesos de metropolización que involucran municipios de más de una Unidad Federativa. Esta figura jurídica es la Región Integrada de Desarrollo.

Palabras clave: Ciudad; Fragmentación territorial; Metropolización.

\section{INTRODUÇÃO}

Uma análise contemporânea do estado de Goiás evidencia uma expressiva diversidade de atividades e processos. Em Goiás, realidades metropolitanas compartilham o 
território com cidades médias e pequenas, produzindo complexas estruturas produtivas em que movimentos ininterruptos redefinem valores, significados e sentidos.

Contudo, é importante destacar que as características supracitadas foram produzidas no curso de poucas décadas. Para um bom entendimento das realidades que hoje se fazem presentes em Goiás é fundamental recordar que seu território esteve inserido, por um bom tempo, na vastidão de terras conhecidas como sertão. A característica goiana relevante para sua inclusão no universo sertanejo era sua distância em relação ao litoral; que, à época, era a porção do território que concentrava a maior parte da população e das atividades econômicas indicadoras da presença de um movimento classificado como civilizador.

Para Moraes (2003), não é possível delimitar de maneira precisa as localidades sertanejas; mas o sertão era uma condição atribuída a uma expressiva extensão de terras. Tratava-se de uma qualificação imposta, de uma ideologia geográfica promotora de depreciações espacialmente referenciadas.

Somente no século XVIII os primeiros núcleos de povoamento foram implementados em Goiás: os arraiais da Barra e de Sant'Ana, que, em 1739, deram origem à Vila Boa de Goiás (LUZ, 2012). Quanto ao processo de incorporação do território goiano por sistemas econômicos sediados no litoral, Bertran (1988, p. 19) esclarece que:

A partir de 1736 [...] com a abertura da estrada Goiás-Cuiabá, começam a definir-se melhor os contornos regionais, existindo, via Goiás, comunicações habituais com São Paulo, Bahia e Minas Gerais, além das rotas monçoneiras, fluviais, entre Mato Grosso e São Paulo. Começam a definir-se também os núcleos mineratórios, criando-se pequenos centros regionais como Goiás-Velho, Pilar, Meia Ponte (Pirenópolis), Luziânia, Traíras (Niquelândia), Arraias e Natividade, todos em Goiás $[\ldots]$.

Em 1748, finalmente, foram instaladas as capitanias de Goiás e de Mato Grosso, com administrações independentes de São Paulo. Por essa época, a decadência da mineração em Minas Gerais contribuía de certa forma para a sedimentação dessas economias auríferas alternativas, que tiveram fôlego por cerca de mais duas décadas em relação a Minas, como condutoras tardias da mineração colonial.

De acordo com Luz (2012, p. 15):

[...] a inserção do Centro-Oeste e, em específico, do território goiano a partir de meados do século XVIII, no sistema produtivo nacional, se respalda pela dinâmica expansionista do capitalismo. [...] cada etapa do processo de apropriação e transformação do território goiano se articula a um determinado momento e acontecimento em curso na esfera nacional e, em particular, no centro dinâmico do país.

Naquele momento, migrantes provenientes do Sudeste e Nordeste do país (BERTRAN, 1978, 1988; LUZ, 2012) estabeleceram atividades comerciais vinculadas ao 
universo minerador. Contudo, os núcleos mineradores entraram em decadência na transição do XVIII para o século XIX (BERTRAN, 1978; LUZ, 2012), promovendo uma alteração no cenário produtivo.

De acordo com Luz (2012, p. 16):

[...] A saída para crise que se instalou foi a atividade agropastoril, principalmente, a pecuária extensiva, em função das características naturais da região e da disponibilidade de amplas áreas para sua prática. Mesmo assim, a segunda fase ligada à produção agropecuária, apesar do desenvolvimento da pecuária, destacavase pela inércia e isolamento.

O presente artigo versa sobre uma realidade urbana, produzida em Goiás, no bojo do movimento minerador do século XVIII. Trata-se do município de Luziânia que, na segunda metade do século XX, foi envolvido por um processo de metropolização centrado na capital federal interiorizada. A partir deste contexto, foi realizada uma análise da fragmentação do território do município de Luziânia, no curso do processo de transformação de uma realidade colonial em realidade metropolitana.

Entre os elementos percebidos como relevantes na investigação realizada - por meio de pesquisas bibliográficas, análises de documentos e trabalhos de campo - três foram destacados: os movimentos migratórios caracterizados por distintas escalas, as fragmentações territoriais e a figura jurídica criada para a gestão de complexas realidades metropolitanas. Os tópicos que seguem detalham como estes elementos redefiniram as relações travadas no território goiano diretamente afetado pela presença da nova capital federal.

\section{Luziânia e o processo de metropolização de uma cidade colonial.}

Segundo a Enciclopédia dos Municípios Brasileiros do IBGE (1958), a formação do território de Luziânia deveu-se, principalmente, ao paulista Antônio Bueno de Azevedo, falecido em 12 de maio de 1771. No final de 1746, o paulista, acompanhado de amigos e escravos, partiu de Piracatu (atual Paracatu/MG), rumo ao noroeste, até chegar às margens de um rio, que, naquele momento, recebeu o nome de São Bartolomeu, em homenagem ao santo do dia. Na área de influência direta do rio, Antônio Bueno de Azevedo formou roças e alguns ranchos (IBGE, 1958).

Em 11 de dezembro de 1746, o grupo seguiu rumo ao oeste. Após dois dias de viagem, resolveram fixar residência em um local batizado com o nome de Santa Luzia. Nesta 
localidade, a atividade mineradora desenvolvida foi tão intensa que, rapidamente, originou um arraial habitado por uma população de 10.000 pessoas, incluindo os escravos (IBGE, 1958).

Uma Portaria de 30 de outubro de 1749 elevou Santa Luzia à categoria de Julgado. Por meio do Alvará de 21 de dezembro de 1756, foi erigida a freguesia de natureza coletiva. Em 06 de dezembro de 1758, Santa Luzia foi elevada à categoria de Comarca Eclesiástica. Em $1^{\circ}$ de abril de 1833, o arraial foi elevado à condição de Vila pela Resolução do Conselho do Governo (instalado solenemente em 7 de abril de 1834). E, finalmente, em 05 de outubro de 1867, a Vila passou à categoria de Cidade (IBGE, 1958). O mapa 01 apresenta a localização/situação de Santa Luzia no território da Província de Goyaz, no ano de 1872.

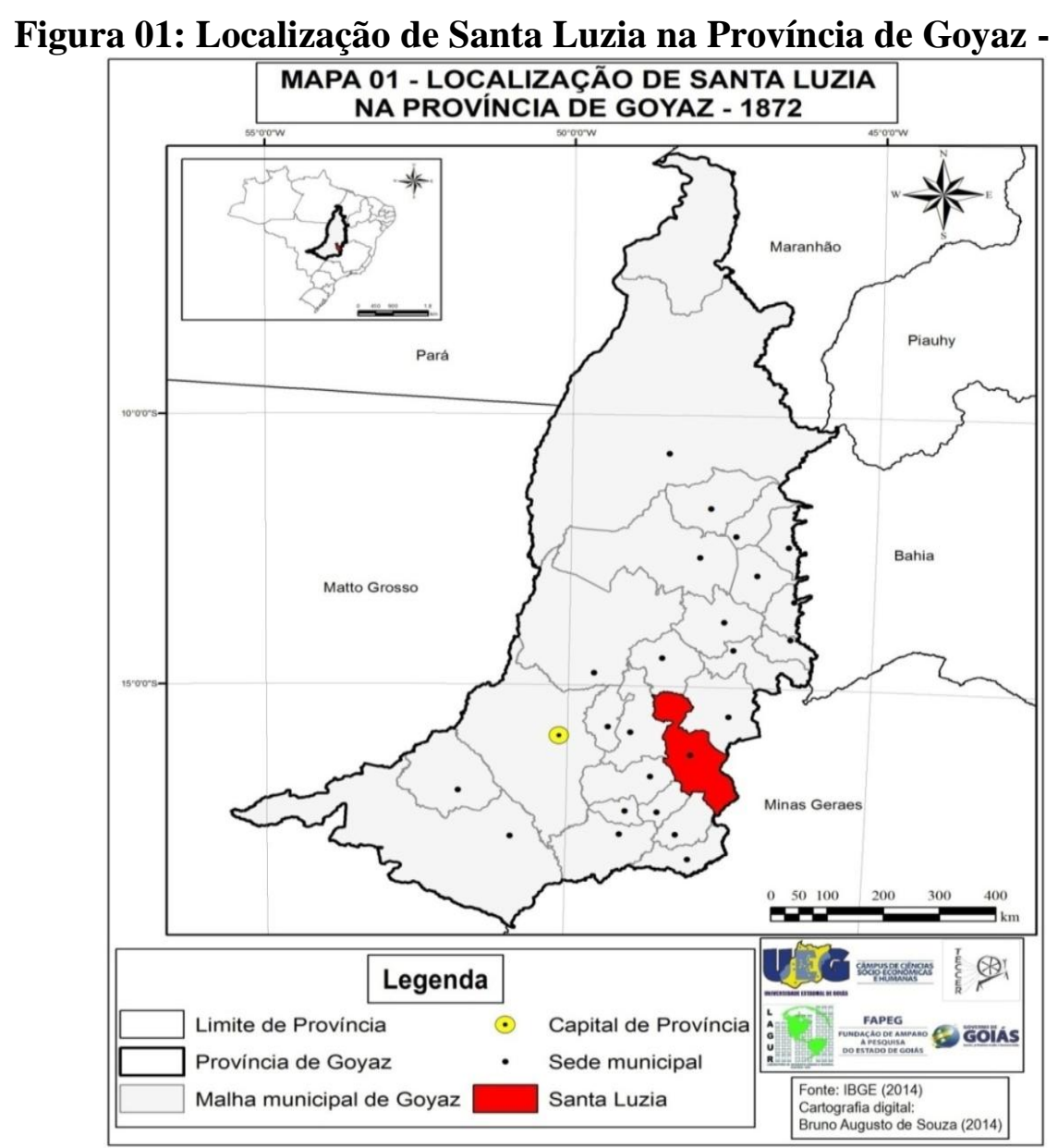

Fonte: IBGE (2014). Organização: Bruno Augusto de Souza (2014).

No final do século XVIII, a mineração começou a declinar. Muitas famílias abandonaram o arraial e se fixaram na zona rural, dedicando-se à lavoura e à criação de gado (IBGE, 1958). Com relação às atividades econômicas desenvolvidas em Santa Luzia, SaintHilaire (1937, p. 326-327) descreveu o cenário por ele encontrado no ano de 1819: 
[...] quando estive [...] na parochia de Santa Luzia, onde existem vastas pastagens naturaes, os habitantes se queixavam de não se poderem desfazer das boiadas sinão enviando-as a Bambuhy ou a Formiga, afastadas de cerca de 130 a 146 leguas e, por conseguinte, de só retirarem lucros insignificantes.

Desde sua fundação até 1850, Santa Luzia esteve vinculada à Comarca de Vila Boa. Em 19 de julho de 1850, Santa Luzia foi incorporada a Comarca de Corumbá de Goiás, com sede em Bonfim (atual Silvânia), por meio de Lei Provincial. Em 29 de julho de 1871, a Lei no 492 criou a Comarca de Imperatriz (Formosa), com sede em Luziânia. Em 1892, a Lei estadual $n^{\mathbf{0}} 22$, criou a Comarca de Lagoa Formosa, passando a sede da Comarca de Luziânia para aquela cidade. Em 25 de julho de 1907, por meio da Lei $\mathrm{n}^{\mathbf{o}}$ 306, foi reestabelecida a Comarca de Santa Luzia, com sede na mesma cidade, sendo instalada em 04 de fevereiro de 1908. Por força do Decreto-Lei estadual no 8.305, de 31 de dezembro de 1943, Santa Luzia passou a denominar-se Luziânia (IBGE, 1958).

Na data da publicação da Enciclopédia dos Municípios Brasileiros, pelo IBGE, em 1958, a influência exercida por Brasília no território de Luziânia já era destacada, a partir da constatação do crescimento de sua população, que passou a receber migrantes de municípios goianos e de outros estados (Tabela 01) (IBGE, 1958). Esse crescimento foi intensificado na transição das décadas de 1970 para 1980, bem como das décadas de 1980 para 1990. É interessante destacar que parte expressiva do território do Distrito Federal (Brasília) pertencia a Luziânia (Mapa 02):

Tabela 01 - Evolução populacional de Luziânia (antiga Santa Luzia): 1872-2014

\begin{tabular}{|c|c|c|c|c|c|c|c|c|c|c|c|}
\hline \multirow{3}{*}{$\begin{array}{l}\text { Santa } \\
\text { Luzia }\end{array}$} & \multicolumn{3}{|c|}{1872} & \multirow{2}{*}{$\begin{array}{l}1900 \\
\text { Pop. } \\
\text { total }\end{array}$} & \multirow{2}{*}{\multicolumn{2}{|c|}{$\begin{array}{l}1920 \\
\text { Pop. } \\
\text { total }\end{array}$}} & \multicolumn{5}{|c|}{1940} \\
\hline & $\begin{array}{l}\text { Pop. } \\
\text { livre }\end{array}$ & $\begin{array}{l}\text { Pop. } \\
\text { escrava }\end{array}$ & $\begin{array}{l}\text { Pop. } \\
\text { total }\end{array}$ & & & & \multicolumn{2}{|c|}{$\begin{array}{l}\text { Pop. } \\
\text { urbana }\end{array}$} & \multicolumn{2}{|c|}{ Pop. rural } & Pop. total \\
\hline & 6.071 & 432 & 6.503 & \multicolumn{3}{|c|}{12.461} & \multicolumn{2}{|c|}{1.554} & \multicolumn{2}{|c|}{15.695} & 17.249 \\
\hline \multirow{9}{*}{ Luziânia } & \multicolumn{3}{|c|}{1950} & \multicolumn{4}{|c|}{1960} & \multicolumn{4}{|c|}{1970} \\
\hline & $\begin{array}{c}\text { Pop. } \\
\text { urbana }\end{array}$ & $\begin{array}{l}\text { Pop. } \\
\text { rural }\end{array}$ & $\begin{array}{l}\text { Pop. } \\
\text { total }\end{array}$ & $\begin{array}{c}\text { Pop. } \\
\text { urbana }\end{array}$ & $\begin{array}{l}\text { Pop. } \\
\text { rural }\end{array}$ & & & & & $\begin{array}{l}\text { Pop. } \\
\text { rural }\end{array}$ & $\begin{array}{l}\text { Pop. } \\
\text { total }\end{array}$ \\
\hline & 1.811 & 17.846 & 19.657 & 5.068 & 22.816 & & 384 & & & 23.203 & 32.807 \\
\hline & \multicolumn{3}{|c|}{1980} & \multicolumn{4}{|c|}{1991} & \multicolumn{4}{|c|}{2000} \\
\hline & $\begin{array}{c}\text { Pop. } \\
\text { urbana }\end{array}$ & $\begin{array}{l}\text { Pop. } \\
\text { rural }\end{array}$ & $\begin{array}{l}\text { Pop. } \\
\text { total }\end{array}$ & $\begin{array}{c}\text { Pop. } \\
\text { urbana }\end{array}$ & $\begin{array}{l}\text { Pop. } \\
\text { rural }\end{array}$ & & & & & $\begin{array}{l}\text { Pop. } \\
\text { rural }\end{array}$ & $\begin{array}{l}\text { Pop. } \\
\text { total }\end{array}$ \\
\hline & 75.977 & 16.840 & 92.817 & 194.345 & 13.329 & & 674 & & 165 & 10.917 & 141.082 \\
\hline & \multicolumn{3}{|c|}{2010} & \multicolumn{2}{|c|}{2014} & & & & & & \\
\hline & $\begin{array}{c}\text { Pop. } \\
\text { urbana }\end{array}$ & $\begin{array}{l}\text { Pop. } \\
\text { Rural }\end{array}$ & $\begin{array}{l}\text { Pop. } \\
\text { total }\end{array}$ & \multicolumn{2}{|c|}{$\begin{array}{c}\text { Pop. total } \\
\text { (estimativa) }\end{array}$} & & & & & & \\
\hline & 162.807 & 11.724 & 174.531 & \multicolumn{2}{|c|}{191.139} & & & & & & \\
\hline
\end{tabular}

Fonte: IBGE (2014). Organização: Bruno Augusto de Souza (2015). 
Figura 02: Localização de Luziânia e do atual Distrito Federal (Brasília) em Goiás 1950

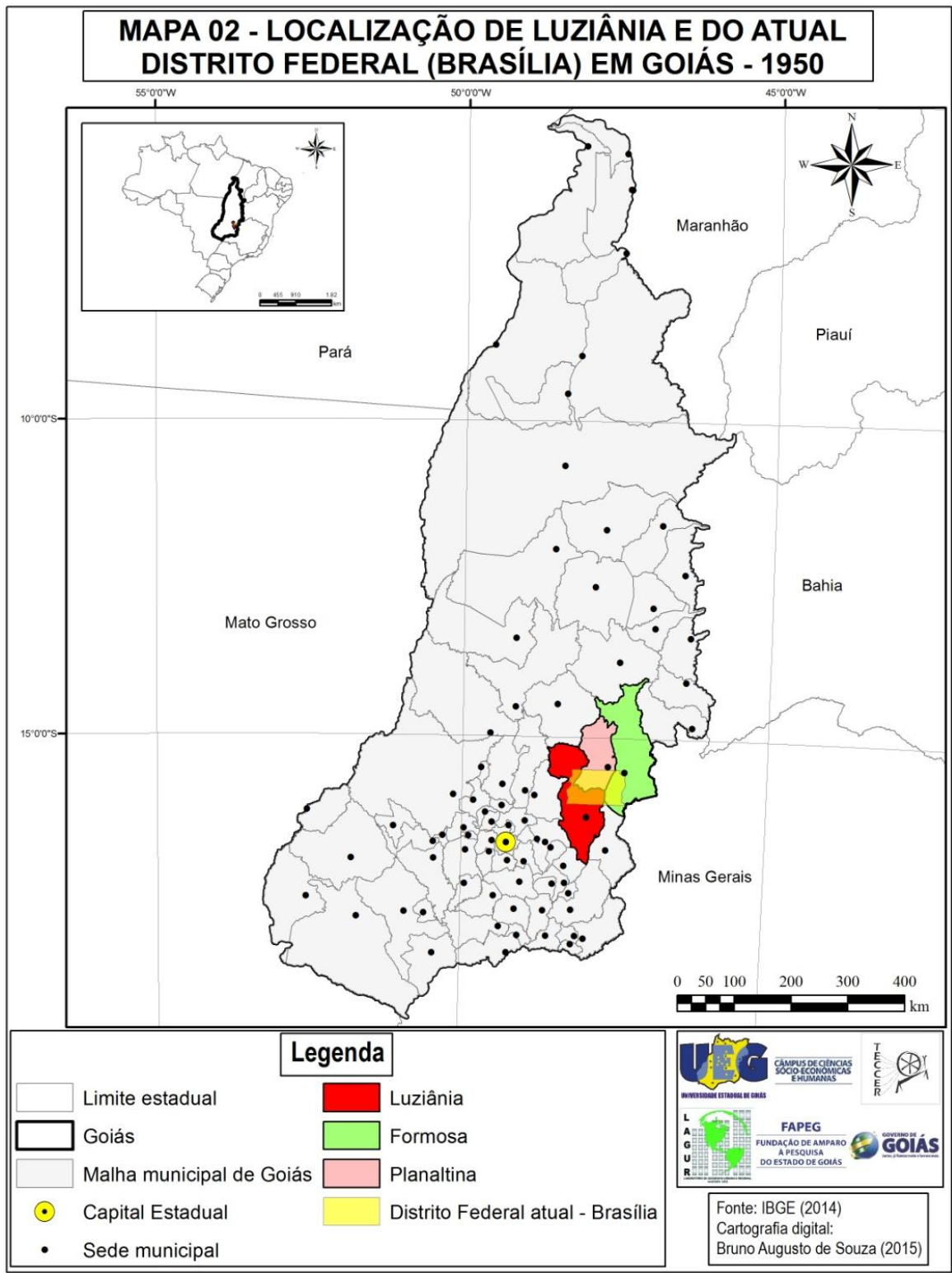

Fonte: IBGE (2014). Organização: Bruno Augusto de Souza (2015).

O intenso fluxo migratório atraído pela nova capital afetou o município de Luziânia. As levas de migrantes de Goiás e de outros estados brasileiros incrementaram seu quantitativo populacional. O vasto território do município e a proximidade com Brasília fizeram com que nele fossem construídos conjuntos habitacionais destinados a abrigar os migrantes indesejados que partiram rumo à nova cidade-capital. Estes conjuntos habitacionais tornaram-se embriões para alguns municípios criados na década de 1990. Mas o processo fragmentador foi deflagrado na década de 1980, com a criação do município de Santo Antônio do Descoberto (MELLO, 2009). 
Brasília, Luziânia e as repercussões territoriais de uma metropolização (in)desejada

Como destacado anteriormente, o território de Luziânia originou cinco outros municípios (Mapa 03), que são: Santo Antônio do Descoberto (1982), Cidade Ocidental (1991), Valparaíso de Goiás (1995) e Novo Gama (1995). Em 1995, foi a vez de Santo Antônio do Descoberto ter seu território fragmentado, abrindo espaço para a criação de Águas Lindas de Goiás. Com as fragmentações, a população de Luziânia decresceu na década de 1990: em 1991, a população era de 207.674 habitantes, e, em 2000, após as fragmentações, o contingente populacional caiu para 141.082 habitantes.

Figura 03: Localização de Luziânia e os municípios originados das fragmentações - 1980

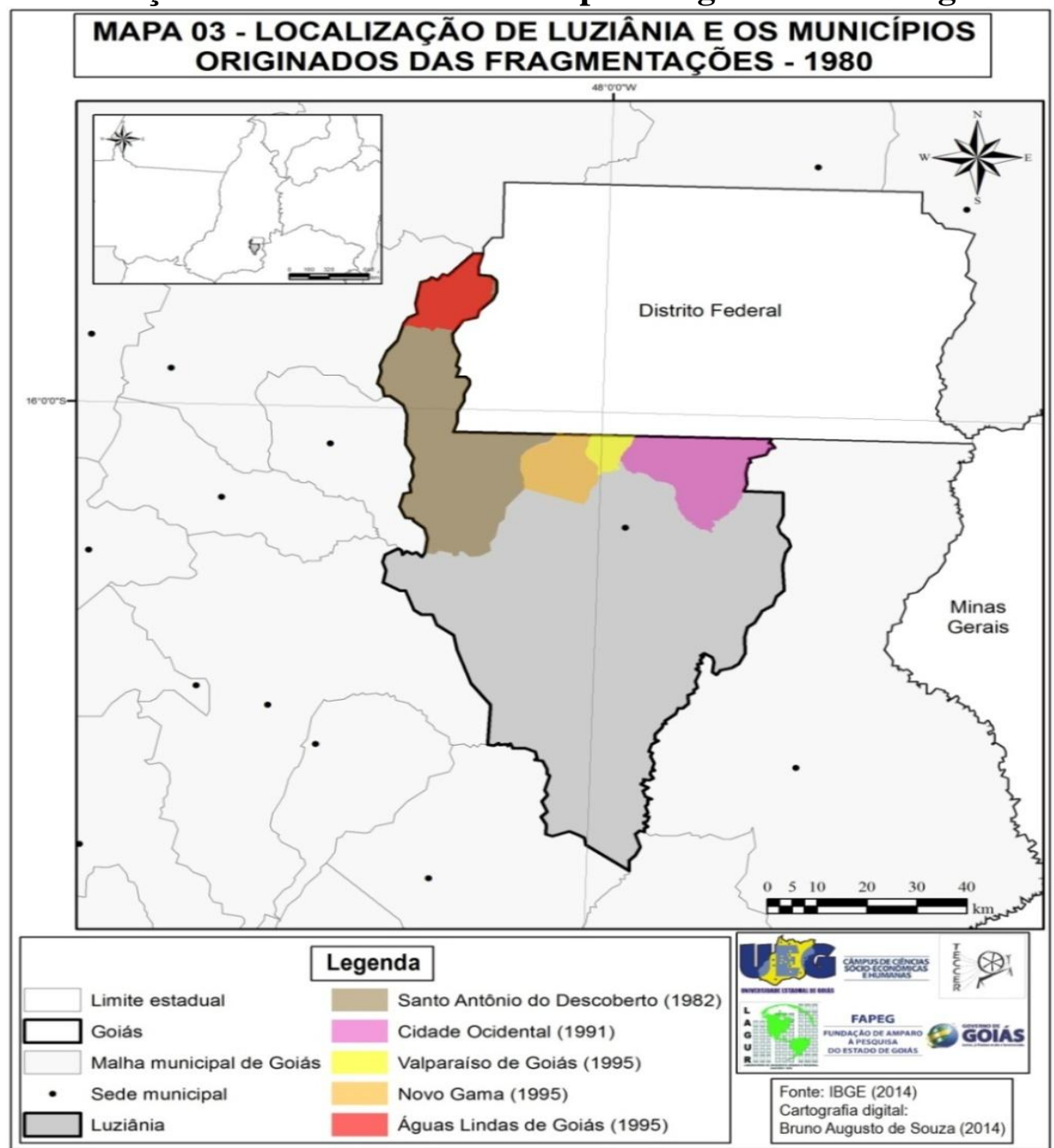

Fonte: IBGE (2014). Organização: Bruno Augusto de Souza (2014).

Contudo, a população do município seguiu apresentando um forte ritmo de crescimento: em 2010, a população era de 174.531 habitantes e, em 2014, a população estimada, de acordo com dados do IBGE (2014a), alcançou o contingente de 191.139 
habitantes. Assim, vê-se que a população de Luziânia continuou em crescimento, mesmo com a fragmentação do município.

O crescimento populacional de Luziânia e a fragmentação territorial imposta ao município evidenciam a repercussão da interiorização da capital federal no estado de Goiás. As cidades produzidas no contexto do parcelamento do território de Luziânia foram envolvidas por um processo de metropolização; que, para Moura (2014, p. 40), é "um estágio da urbanização, é o processo que confere características metropolitanas ao espaço". De acordo com Firkowski (2013, p. 28), "[...] a metropolização pode ser compreendida como o processo de concentração e urbanização massivas".

No Brasil, assim como em outros países, a urbanização massiva (FIRKOWSKI, 2013) trouxe consigo a necessidade de normas específicas para a regulação das complexas relações territorializadas. Galvão et al. (1969) afirmam que o processo de metropolização nada mais é que o próprio processo de urbanização; que, a partir de certo momento, se torna muito complexo, o que gera graves problemas de integração entre o núcleo central da área e os municípios vizinhos. Decorre daí as demandas por normas direcionadas para a gestão compartilhada de territórios de municípios autônomos, visando à integração de serviços de interesse comum.

Para regular as relações metropolitanas brasileiras foi criada, em 1973, uma figura jurídica: a Região Metropolitana. As primeiras Regiões Metropolitanas foram criadas pelo Poder Legislativo Federal, em um momento marcado pela centralização das estruturas políticas.

A partir da Constituição Federal de 1988, houve uma descentralização no que se refere à criação e gestão das Regiões Metropolitanas, que passaram a ser produto do Poder Legislação Estadual. Em um momento posterior, em 1998, uma nova figura jurídica foi criada: a Região Integrada de Desenvolvimento, a RIDE. A RIDE surge para possibilitar a gestão de processos de metropolização que envolvem municípios de mais de uma Unidade Federativa, por esta razão está vinculada ao Poder Legislativo Federal (MINISTÉRIO DA INTEGRAÇÃO NACIONAL, 2014a).

A Região Integrada de Desenvolvimento do Distrito Federal e Entorno - RIDEDF (Mapa 04) foi criada pela Lei Complementar $n^{\circ}$ 94, de 19 de fevereiro de 1998, e regulamentada pelo Decreto $\mathrm{n}^{\circ} 2.710$, de 04 de agosto de 1998, alterado pelo Decreto $\mathrm{n}^{\circ}$ 3.445, de 04 de maio de 2000. Ela é constituída pelo Distrito Federal e pelos municípios de 
Abadiânia, Água Fria de Goiás, Águas Lindas de Goiás, Alexânia, Cabeceiras, Cidade Ocidental, Cocalzinho de Goiás, Corumbá de Goiás, Cristalina, Formosa, Luziânia, Mimoso de Goiás, Novo Gama, Padre Bernardo, Pirenópolis, Planaltina, Santo Antônio do Descoberto, Valparaíso de Goiás e Vila Boa, no Estado de Goiás, e Unaí, Buritis e Cabeceira Grande, no Estado de Minas Gerais (MINISTÉRIO DA INTEGRAÇÃO NACIONAL, 2014b).

Figura 04: Municípios da RIDE-DF (2015)

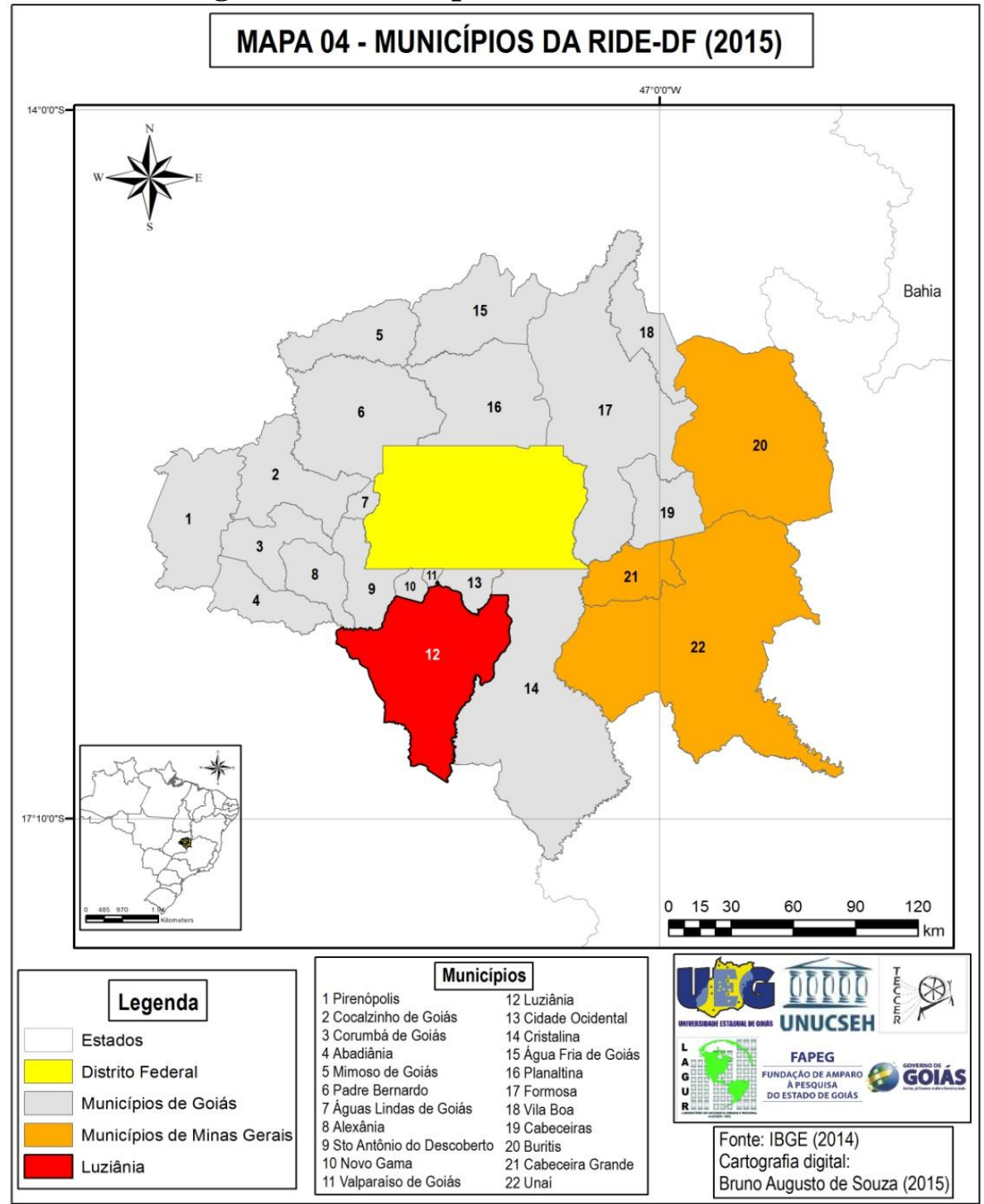

Fonte: IBGE (2014). Organização: Bruno Augusto de Souza (2015).

A capital federal é o núcleo central da RIDE-DF. Esta Região diferencia-se das outras realidades metropolitanas do país. Para um melhor entendimento de relações metropolitanas tão particulares, o próximo tópico apresenta e analisa o processo de 
SOUZA, B. A.; MELLO, M.

Brasília, Luziânia e as repercussões territoriais de uma metropolização (in)desejada

metropolização deflagrado a partir da transferência da capital federal do litoral para o Planalto Central brasileiro.

\section{Da construção de Brasília ao processo de produção de uma realidade metropolitana}

Antes do processo de metropolização deflagrado pela construção de Brasília, a ausência de uma infraestrutura minimamente eficiente de transportes isolava o Planalto Central dos centros econômicos situados no litoral (LUZ, 2012). De acordo com Maciel (2012, p. 29), "em meados do século XX, a hinterlândia brasileira achava-se pouco povoada, integrando-se de modo precário, econômica e culturalmente, à comunidade nacional".

Na segunda metade do século XX, ocorreu a transferência da capital federal e o início do processo de modernização agrícola nos domínios do Cerrado goiano e brasileiro. Sobre a modernização agrícola, Castillo (2007, p. 35) enfatiza a existência de dois períodos:

[...] o primeiro período abrange aproximadamente as décadas de 1960 e 1970 e caracteriza-se pela constituição do chamado complexo agroindustrial. Esse paradigma é marcado pela forte presença do Estado na articulação entre os agentes envolvidos nos circuitos produtivos modernos, gerando uma maior aproximação e interdependência entre agricultura e indústria.

O segundo período (o atual) é o de consolidação da produção de commodities nos Cerrados. A partir dos anos 1980, a forte crise fiscal do Estado brasileiro impele [...] a uma mudança nas formas de intervenção no setor agrícola.

Abordando a especificidade de Brasília, Mello (2009, p. 20) afirma que:

No dia 21 de abril de 1960, foi inaugurada, no Planalto Central brasileiro, a nova capital da república. Brasília, chamada também de "capital da esperança" pelo escritor francês André Malraux, foi a terceira capital brasileira. Antes dela, Salvador-BA e Rio de Janeiro-RJ tinham ocupado este posto. A partir da data da inauguração da capital interiorana, iniciou-se a transferência de parte dos órgãos componentes dos poderes executivo, legislativo e judiciário federais. Já estavam concluídas as suntuosas edificações que os abrigariam na nova sede administrativa do Estado.

Com a transferência da capital federal do Rio de Janeiro para Brasília, o processo de apropriação capitalista do Planalto Central brasileiro foi acelerado. Essa apropriação territorial foi efetivada através da penetração do capital, que alterou a estrutura produtiva por meio de Programas Governamentais, como: o Programa de Desenvolvimento do Cerrado Polocentro e o Programa de Cooperação Nipo-Brasileira para o Desenvolvimento dos Cerrados - Prodecer. O Estado promoveu a transformação dos Cerrados em área de aptidão agrícola, com vistas ao incremento da exportação (BARREIRA e BORGES, 2013). 
Os investimentos induziram expressivos fluxos migratórios. Brasília, na condição de capital federal, atraiu migrantes de diversos estados brasileiros. No dia da inauguração da nova capital - 21 de abril de 1960 -, Taguatinga, Sobradinho e Gama eram núcleos urbanos consolidados. Segundo o projeto original, núcleos como estes deveriam ser constituídos somente vinte anos após a inauguração de Brasília; ou seja, a partir de 1980 (MELLO, 2009).

O quantitativo populacional que migrou em direção a capital federal reconfigurou o território goiano, pois grande parte dos migrantes não se fixou no interior do Distrito Federal, mas em municípios goianos de seu entorno. Novos arranjos territoriais demonstram que a população urbana dos municípios goianos, próximos a Brasília, cresceu de forma acelerada, principalmente quando consideramos os municípios cortados pelas rodovias BR040 e BR-060.

No curso do processo urbanizador, a década de 1970 aparece como divisora de águas no estado de Goiás. Nela a população urbana cresce significativamente, se aproximando da população rural (Tabela 02). Após o período citado, a população urbana ultrapassa a rural.

Tabela 02 - População rural e urbana no estado de Goiás: 1940-2010

\begin{tabular}{c|c|c|c|c|c|c|c|c}
\hline & $\mathbf{1 9 4 0}$ & $\mathbf{1 9 5 0}$ & $\mathbf{1 9 6 0}$ & $\mathbf{1 9 7 0}$ & $\mathbf{1 9 8 0}$ & $\mathbf{1 9 9 1}$ & $\mathbf{2 0 0 0}$ & $\mathbf{2 0 1 0}$ \\
\hline Rural & 539.618 & 791.510 & 1.084 .907 & 1.325 .765 & 1.056 .254 & 771.443 & 605.779 & 583.074 \\
\hline Urbana & 122.400 & 219.370 & 541.469 & 1.134 .242 & 2.172 .965 & 3.241 .119 & 4.390 .660 & 5.420 .714 \\
\hline Total & 662.018 & 1.010 .880 & 1.626 .376 & 2.460 .007 & 3.229 .219 & 4.012 .562 & 4.996 .439 & 6.003 .788 \\
\hline
\end{tabular}

Fonte: IBGE (2014b); Ipeadata (2014). Organização: Bruno Augusto de Souza (2014)

Uma expressiva expansão urbana, em uma sociedade marcada pela desigualdade na distribuição de renda, repercutiu na produção do espaço urbano e na mobilidade entre as cidades. Um considerável contingente populacional assumiu a condição permanente de migrante pendular, com vistas ao atendimento das necessidades voltadas para a reprodução de sua existência (MELLO, 2009).

A migração pendular é aquela em que o indivíduo se desloca diariamente para um município distinto do que ele reside, para trabalhar e/ou estudar. A respeito desta modalidade de migração, Ojima, Pereira e Silva (2008, p. 4) afirmam que "[...] essa modalidade é normalmente denominada 'deslocamento pendular' por se considerar que trabalhando ou estudando em municípios distintos este movimento possui uma regularidade cotidiana". 
A migração pendular está fortemente presente na vida dos habitantes de municípios como Valparaíso de Goiás: segundo o IBGE, 54\% de sua população está inserida neste movimento diário. É importante ressaltar que a intenção original dos migrantes que fixaram residência nos municípios goianos da RIDE-DF era morar no Distrito Federal. Contudo, o elevado custo de vida impediu a concretização do desejo inicial. Assim, os migrantes atraídos por Brasília não conseguiram fixar residencial na capital federal. Como alternativa, passaram a residir em municípios goianos da RIDE-DF. Contudo, estes municípios não são caracterizados pela oferta de emprego e de serviços públicos essenciais. Para reproduzir suas vidas, os migrantes são compelidos ao deslocamento pendular.

\section{CONSIDERAÇÕES FINAIS}

Com a transferência da capital federal para Brasília, o território goiano passou por profundas transformações. Como exemplo representativo das metamorfoses territorializadas, o município de Luziânia apresenta uma história profundamente interessante: sua origem está atrelada as atividades mineradoras desenvolvidas no século XVIII e, após a edificação da nova capital federal, teve seu território fragmentado por força do processo metropolizador.

A fragmentação de Luziânia originou cinco municípios: Santo Antônio do Descoberto, Cidade Ocidental, Valparaíso de Goiás, Novo Gama e Águas Lindas de Goiás. Atualmente, a população de três destes municípios ultrapassa 100.000 habitantes: Valparaíso de Goiás, Águas Lindas de Goiás e Novo Gama. Este dado é importante porque as fragmentações promovidas foram repercussões do crescimento populacional estabelecido a partir da atração exercida pela "capital da esperança".

No decorrer de poucas décadas, realidades urbanas recém-criadas passaram a exigir expressivos recursos do Tesouro Estadual goiano, com vistas ao oferecimento de serviços de educação, saúde, segurança, dentre outros. A criação da RIDE-DF ainda não possibilitou a gestão compartilhada de serviços interesse comum entre os entes que a compõem.

O que vigora é a articulação de ações segregadoras e conflituosas. Mais de 1.100.000 cidadãos residentes em municípios goianos gravitam no interior desta realidade 
metropolitana centrada em Brasília. Assim, o que prevalece não é o interesse comum, mas os interesses de agentes particulares inseridos em um contexto profundamente complexo.

\section{AGRADECIMENTOS}

À Fundação de Amparo à Pesquisa do Estado de Goiás - FAPEG -, pela concessão de Bolsa de Estudos ao primeiro autor e à Universidade Estadual de Goiás, pela concessão de Bolsa de Incentivo à Pesquisa ao segundo autor.

\section{REFERÊNCIAS}

BARREIRA, Celene Cunha Monteiro Antunes; BORGES, Elcileni de Melo. Dinâmica metropolitana no Centro-Oeste: concentração, produção habitacional e reconfiguração urbana em Goiânia e Brasília. In: XV ENANPUR Desenvolvimento, Planejamento e Governança (XXX anos ANPUR), 2013, Recife-PE. Anais... Recife-PE: ANPUR, v. 1, 2013, p. 526-543.

BERTRAN, Paulo. Formação econômica de Goiás. Goiânia: Oriente, 1978.

Uma introdução à história econômica do Centro-Oeste do Brasil. Brasília: CODEPLAN, Goiás: UCG, 1988.

BRASIL. Constituição da República Federativa do Brasil, de 5 de outubro de 1988. Disponível em: 〈http://www.planalto.gov.br/ccivil_03/constituicao/Constituicao.htm>. Acesso em maio/2014.

CASTILLO, Ricardo. Agronegócio e logística em áreas de Cerrado: expressão da agricultura científica globalizada. Revista da ANPEGE, v. 3, 2007, p. 33-43.

FIRKOWSKI, Olga Lúcia Castreghini de Freitas. Metrópoles e regiões metropolitanas no Brasil: Conciliação ou divórcio? In: FURTADO, Bernardo Alves; KRAUSE, Cleandro; FRANÇA, Karla Christina Batista de (Org.). Território metropolitano, políticas municipais: por soluções conjuntas de problemas urbanos no âmbito metropolitano. Brasília: Ipea, 2013, p. 21-51.

GALVÃO, Marília Velloso; FAISSOL, Speridião; LIMA, Olga Maria Buarque de; ALMEIDA, Elisa Maria José Mendes de. Áreas de pesquisa para determinação de áreas metropolitanas. Revista Brasileira de Geografia, Rio de Janeiro, 31 (4), p. 53-127, 1969.

INSTITUTO BRASILEIRO DE GEOGRAFIA E ESTATÍSTICA (IBGE). Enciclopédia dos Municípios Brasileiros. Volume XXXVI. Rio de Janeiro, 1958. 
Cidades. Disponível em <http://www.cidades.ibge.gov.br/xtras/home.php>. Acesso em set.-out./2014a.

SIDRA - Censos demográficos de 2000 e 2010. Disponível em

$\langle$ http://www.sidra.ibge.gov.br/cd/cd2000cgp.asp?o=27\&i=P>. Acesso em nov./2014b.

INSTITUTO DE PESQUISA ECONÔMICA APLICADA (IPEA). Ipeadata. Disponível em <http://www.ipeadata.gov.br/>. Acesso em out./2014.

/IBGE/UNICAMP. Caracterização e tendências da rede urbana do Brasil:

configurações atuais e tendências da rede urbana. Brasília: IPEA, 2001.

LUZ, Janes Socorro da. Os caminhos do desenvolvimento e modernização do território: a dinâmica territorial e a urbanização em Goiás. In: SILVA, Ademir Luiz da; OLIVEIRA, Eliézer Cardoso de; MELLO, Marcelo de (orgs.). Território, Cidades e Cultura no Cerrado. Anápolis: UEG, 2012, p. 13-28.

MACIEL, Dulce Portilho. Estado e território na hinterlândia brasileira: as ações da Fundação Brasil Central (FBC) - 1943-1967. In: SILVA, Ademir Luiz da; OLIVEIRA, Eliézer Cardoso de; MELLO, Marcelo de (orgs.). Território, Cidades e Cultura no Cerrado. Anápolis: UEG, 2012, p. 29-52.

MELLO, Marcelo de. Brasília, Águas Lindas de Goiás e o (Des)Encontro da Racionalidade com a Irracionalidade. Tese (doutorado), Universidade Federal de Goiás, Instituto de Estudos Sócio-Ambientais, Programa de Pós-graduação em Geografia, Goiânia, 2009.

O Homem e a Razão instrumental no processo de apropriação da natureza do Cerrado. In: SILVA, Ademir Luiz da; OLIVEIRA, Eliézer Cardoso de; MELLO, Marcelo de (orgs.). Território, Cidades e Cultura no Cerrado. Anápolis: UEG, 2012, p. 53-62.

MINISTÉRIO DA INTEGRAÇÃO NACIONAL/SECRETARIA DE DESENVOLVIMENTO REGIONAL. Regiões Integradas de Desenvolvimento - RIDEs. Disponível em <http://www.integracao.gov.br/regioes_integradas_rides >. Acesso em jul./2014a.

Região Integrada de Desenvolvimento do Distrito Federal e Entorno - RIDEDF. Disponível em <http://www.integracao.gov.br/web/guest/regioes_integradas_df_rides>. Acesso em jul./2014b.

MORAES, Antonio Carlos Robert, O Sertão: um "outro" geográfico. Terra Brasilis, n. 4-5, jan./dez., 2003.

MOURA, Rosa. Questões sobre a formação de regiões metropolitanas. In: DIAS, Patrícia Chame; LOPES, Diva Maria Ferlin (orgs.). Cidades médias e pequenas: desafios e possibilidades do planejamento e gestão. Salvador: SEI, 2014, p. 39-58. 
OJIMA, Ricardo; PEREIRA, Rafael Henrique Moraes; SILVA, Robson Bonifácio da. Cidades-dormitório e a mobilidade pendular: espaços da desigualdade na redistribuição dos riscos socioambientais? In: Encontro Nacional de Estudos Populacionais, 16., 2008, Caxambú-MG. Anais... Caxambú: ABEP, 2008, p. 1-19.

SAINT-HILAIRE, Auguste de. Viagem às nascentes do Rio São Francisco e pela província de Goyaz. v. 1. São Paulo: Companhia Editora Nacional, 1937. Disponível em $<$ http://www.brasiliana.com.br/obras/viagem-as-nascentes-do-rio-sao-francisco-e-pelaprovincia-de-goias-1-v/pagina/5/texto>. Acesso em dez./2014.

SANTOS, Milton; SILVEIRA, María Laura. O Brasil: território e sociedade no início do século XXI. 9ª ed. Rio de Janeiro: Record, 2006.

SILVA, Eliete Barbosa de Brito. Valparaíso de Goiás-GO: o lugar das identidades, as identidades do lugar 1995-2010. Dissertação (Mestrado), Universidade Federal de Goiás, Departamento de História, Programa de Pesquisa e Pós-graduação em História, Goiânia, 2014.

\section{Autores}

Bruno Augusto de Souza - Possui Graduação em Geografia, Mestrado em Ciências Sociais e Humanidades, ambos cursados pela Universidade Estadual de Goiás (UEG). Atualmente é Doutorando em Geografia pela Universidade Federal de Goiás (UFG).

Marcelo de Mello - Possui Graduação, Mestrado e Doutorado em Geografia, todos cursados pela Universidade Federal de Goiás (UFG). Atualmente é Professor do Curso de Geografia e do Programa de Pós-Graduação em Ciências Sociais e Humanidades da Universidade Estadual de Goiás (UEG).

Artigo recebido em: 31 de julho de 2017.

Artigo aceito em: 01 de novembro de 2017. 